\title{
PRESUPUESTOS PARA EL RECONOCIMIENTO DE LA JURISPRUDENCIA COMO FUENTE DEL ORDENAMIENTO JURÍDICO CUBANO**
}

\author{
RECOGNITION OF BINDING PRECEDENT \\ AS A SOURCE OF LAW IN CUBAN LAW \\ Carlos Justo BRUZÓn VILTRES**
}

\section{Resumen:}

El presente artículo se enfoca en el debate hacia el reconocimiento de la jurisprudencia como fuente formal del Derecho cubano. Parte del necesario análisis de la indeterminación del sistema de fuentes del ordenamiento jurídico, proponiendo un sencillo esquema lógico de solución. Estos elementos sirven de base para la fijación de presupuestos para reconocer a la jurisprudencia dentro del sistema de fuentes formales. Con este estudio se pretende contribuir al proceso de actualización del modelo jurídico cubano, que no puede estar al margen de elementos formales que garanticen un rediseño sistémico e integral del mismo.

\section{Palabras clave:}

Jurisprudencia, reconocimiento de decisiones judiciales, ordenamiento jurídico, fuentes del derecho, Poder Judicial, Cuba.

* Artículo recibido el 20 de febrero de 2014 y aceptado para su publicación el 29 de octubre de 2014.

** Decano de la Facultad de Ciencias Sociales y Humanísticas de la Universidad de Granma, Cuba. Profesor de Teoría general del derecho. Miembro Asociado de la Academia de Ciencias de Cuba. E-mail: cbruzonv@udg.co.cu. 


\section{CARLOS JUSTO BRUZÓN VILTRES}

\section{Abstract:}

The topic of this article is precedent as a source of law in Cuban Law. My first aim is to discuss indeterminacy in the sources of law of a legal system in light of a logical solution to the problem. I claim that precedent must be recognized as a formal source of law and with this I try to join the arguments that propose a needed update and amendment of the Cuban legal system.

\section{Keywords:}

Binding Precedents, Recognition of Judicial Decisions, Legal Order, Sources of Law, Judiciary, Cuba. 
Sumario: I. Punto de partida: indeterminación del sistema de fuentes del ordenamiento jurídico cubano. II. Esquema lógico de solución: determinación, fijación de presupuestos, reconocimiento. III. Posiciones doctrinales internas en torno a la determinación de las fuentes del derecho y de la jurisprudencia en particular. IV. Fijación de presupuestos para el reconocimiento de la jurisprudencia como fuente formal. V. Necesidad del reconocimiento constitucional de la jurisprudencia como fuente formal del ordenamiento jurídico cubano. VI. A manera de conclusiones. VII. Bibliografia.

\section{Punto DE PARTIDA: INDETERMinAción DEL Sistema DE FUENTES DEL ORDENAMIENTO JURÍDICO CUBANO}

No constituye un hallazgo del autor la conclusión en torno a la indeterminación del sistema de fuentes del derecho en Cuba. Precisamente en esta publicación, ${ }^{1}$ el profesor Pérez Carrillo se ha referido a dos posibles causas, siguiendo en ese sentido los postulados teóricos de H. L. A. Hart: La falta de regulación por parte del legislador — de forma explicitadel mencionado sistema de fuentes $\mathrm{y}$, la propia "textura abierta" del ordenamiento jurídico.

Estas dos situaciones pueden ser admitidas, aunque sin soslayar que en el plano teórico no han sido recibidas pacíficamente. Pudiera tenerse en cuenta además lo que considero una especie de "desfase", partiendo del panorama anterior a la aprobación de la Constitución de la República en 1976, y la realidad posterior a la reforma del Código Civil cubano, en 1987.

Resulta que antes del primer hito jurídico señalado, se encontraba vigente en Cuba el Código Civil español, introducido en la Isla mediante Real Decreto de 31 de julio de

1 Pérez Carrillo, Juan R., "Causas de indeterminación en el sistema de fuentes del derecho", Problema. Anuario de Filosofía y Teoría del Derecho, México, UNAM, núm. 4, 2010, pp. 303-321. 
1889 y que establecía en su Título Preliminar el reconocimiento expreso de las fuentes del derecho. No obstante la poca eficacia que pudiera atribuírsele a esta regulación a la altura de la década de los setenta del pasado siglo - ya se habian extendido en la doctrina y la legislación cubanas algunos cánones importados esquemáticamente bajo el influjo del derecho soviético, y otras tendencias conceptuales que podemos calificar como dogmáticas, derivadas de la noción de derecho socialista que se propugnó en la época-, 2 al menos se regulaban estas fuentes y no existía una disposición de superior jerarquía que negara su validez.

Al promulgarse la nueva Constitución cubana - que ponía fin a un periodo de provisionalidad de casi dos décadas-, se omitió este aspecto, conservando su vigencia aún la norma civil sustantiva. Sin embargo, en 1987, al adoptarse la Ley No. 59 de 16 de julio de 1987, Código Civil de la República de Cuba, se suprimieron los artículos relacionados con las fuentes del ordenamiento jurídico, quedando indeterminados los modos de creación jurídica. A lo sumo estos fueron reducidos - por lo que se deduce del texto constitucional, que no emplea en ningún momento el término "fuente" - al acto normativo.

Este hecho se produce en perfecta consonancia con las corrientes de pensamiento que defendian a ultranza la existencia, como única forma de producción del derecho, de la ley,

2 En esto influyeron notablemente las posiciones reduccionistas sostenidas por varios teóricos del Derecho de la extinta Unión de Repúblicas Socialistas Soviéticas y de otros países del campo socialista y la influencia de algunas obras consideradas "clásicas" en la enseñanza y práctica jurídicas en nuestro país. Una valoración crítica sobre el tema en: Fernández Bulté, Julio, Filosofía del derecho, La Habana, Félix Varela, 2003, pp. 261-295; Mondelo, Walter, "Partir del pasado para explorar el futuro", Revista Temas, núm. 64, julio-diciembre de 2010, pp. 118-121; Carrillo, Yoel y Walter Mondelo, "Del voluntarismo ontológico al positivismo ideológico (una lectura del pensamiento jurídico cubano)", Revista Crítica Juridica, núm. 29, enero-junio de 2010, pp. 181-217. 
reforzando el legalismo típico del sistema continental y rechazando cualquier otra manifestación de creación jurídica.

La postura asumida por varios autores cubanos de la época - como veremos más adelante- así lo demuestra. Sin arribar a un acuerdo siquiera sobre la definición del sistema de fuentes como institución —campo pobremente sistematizado en la Teoría del derecho de entonces, presentes además contradicciones y limitaciones-, se arremetió contra la existencia y validez de cualquier otra fuente jurídica distinta a la ley, especialmente la costumbre y la jurisprudencia.

El centro del problema se trasladó además a una rotunda crítica al sistema capitalista, asumiendo — salvo contadas excepciones- que cualquier modo de creación del derecho distinto a la ley -expresión suprema de la soberanía popular- era incompatible con el sistema socialista y, por ende, imposible de ser reconocido positivamente.

En este escenario el "desfase" al que se ha hecho referencia toma forma desde el momento mismo en que el constituyente de 1976 omitió la regulación del sistema de fuentes y el legislador de 1987 borró del nuevo Código Civil la que provenía de la disposición precedente.

Con absoluta razón ha planteado el profesor Pérez Gallardo que "la carencia de un sistema de fuentes que colme el ordenamiento jurídico ha sido (...) uno de los extremos más endebles del Código Civil cubano", ${ }^{3}$ en contraste con la regulación previa contenida en el Título Preliminar del Código Civil español tras la reforma de 1973, "de primordial valor en la aplicación del derecho". ${ }^{4}$

Por una razón u otra, lo cierto es que estas causas hoy configuran una compleja realidad en el contexto jurídico cubano: La indeterminación de sus fuentes, con profundas consecuencias jurídicas.

${ }^{3}$ Pérez Gallardo, Leonardo et al., Estudios de derecho civil cubano, Madrid, Consejo General del Notariado, 2002, p. 276. 


\section{CARLOS JUSTO BRUZÓN VILTRES}

Una de estas fuentes preteridas es la jurisprudencia, entendiéndose por tal, grosso modo, a las normas de origen judicial, con las particularidades que revisten en el contexto jurídico cubano, como tendrá ocasión de explicarse.

Es por ello que se pretende en el presente artículo plantear algunos presupuestos generales para el reconocimiento de la jurisprudencia como fuente formal del derecho en Cuba. Dado que la admisión de este hecho acarrearia un importante cambio de punto de vista en nuestro derecho respecto a la concepción general de sus fuentes - con efectos no solo en la teoría, sino en la praxis jurídica interna-, 5 se parte de considerar la necesaria fundamentación de presupuestos, que operen a modo de condiciones de existencia, de requisitos, para reconocer positivamente a determinadas manifestaciones jurispru- denciales. Estas son, esencialmente, formadas en la ac- tividad de los órganos judiciales de mayor jerarquía en nuestro país.

La necesidad de un planteamiento de esta naturaleza se localiza en el actual desmontaje del carácter sistémico de nuestro derecho, que desde la perspectiva de sus fuentes se traduce en la pervivencia de un profundo legalismo, que ignora, entre otras cuestiones, la progresiva centralidad del derecho jurisprudencial. ${ }^{6}$ Admitir la jurisprudencia como fuente no solo implicaría asegurar una ampliación del

${ }^{5}$ Cambio que es además, de carácter cultural.

6 Así lo afirman, entre otros, Giuseppe Zaccaria, "La jurisprudencia como fuente de Derecho: una perspectiva hermenéutica", Isonomía, núm. 32 , abril de 2010, p. 106. El hecho de que la jurisprudencia como fuente vaya progresivamente colocándose en una discusión central en la teoría y filosofia jurídicas continentales, es el resultado además de la convergencia de algunos fenómenos como el nuevo constitucionalismo, que le ha dado, en palabras de Hennig Leal, "gran notoriedad y actualidad" a la actividad (y al activismo) judicial. Cfr., Hennig Leal, Mônia Clarissa, "La jurisdicción constitucional entre judicialización y activismo judicial: ¿existe realmente "un activismo" o "el activismo"?, Estudios Constitucionales, Santiago de Chile, vol. 10, núm. 2, 2012, disponible en: $h t t p: / / d x$.doi.org/ 10.4067/S0718-52002012000200011 [consulta de 12 de agosto de 2013].

\section{PROBLEMA}


mapa de fuentes jurídicas, sino además constituiría un medio de complementación del ordenamiento jurídico y de ampliación de las garantias de seguridad jurídica, colocando nuevos medios válidos en manos de los ciudadanos para recurrir en pos de la tutela de sus derechos e in-tereses.

\section{ESQUEMA LÓGICO DE SOLUCIÓN: DETERMINACIÓN, FIJACIÓN DE PRESUPUESTOS, RECONOCIMIENTO}

Ha afirmado Diez Picazo que "La enumeración y establecimiento de la jerarquía de las fuentes es, ante todo, un problema político, porque entraña el especial reconocimiento de un ámbito de poder - poder mandar y poder hacer obedecer - que en última instancia es un poder de naturaleza politica".7

Norberto Bobbio concluye asimismo que "El conocimiento de un ordenamiento jurídico (y también un sector particular de este ordenamiento) parte siempre de la enumeración de sus fuentes". 8

Debido al tradicionalismo imperante en la concepción de las fuentes del derecho, que alcanza lógicamente al ordenamiento jurídico cubano, es necesario abordar, al menos en su generalidad, una posible propuesta en el camino teórico hacia la solución de la indeterminación de las fuentes, para luego dar tratamiento específicamente a la jurisprudencia. De ahí que, intentando transitar de lo general a lo particular, considere necesario detenerme en la siguiente situación: se hace indispensable, en el contexto jurídico cubano actual, proponer algunas pautas que permitan definir una especie de "esquema lógico de solución" al mencionado problema de la indeterminación normativa de las fuentes.

En primer lugar, la determinación de los modos de producción del derecho que puedan estar efectivamente ope-

7 Diez Picazo, Luis y Antonio Gullón, Sistemas de derecho civil, Madrid, Tecnos, 1994, p. 98.

${ }^{8}$ Bobbio, Norberto, Teoría general del derecho, Bogotá, Temis, 1987, p. 158. 


\section{CARLOS JUSTO BRUZÓN VILTRES}

rando en la práctica jurídica en Cuba, lo cual no resulta un proceso sencillo. A mi juicio, la determinación de estas fuentes presupone un primer peldaño que debe conducir, necesariamente, a una formulación teórica en torno a la producción del derecho radicalmente distinta a la que ha venido predominando desde hace décadas en nuestro escenario doctrinal y práctico.

Implica, de inicio, una ruptura con el legalismo propio de nuestro sistema, con el principio dogmáticamente sostenido de imperio de la ley y del legislador — confundido al punto de condicionar su efectividad al desconocimiento de cualquier otro modo de creación normativa, incluso, de supeditar el propio reconocimiento del principio de supremacía constitucional a su ejercicio-.

Esta determinación debe ir acompañada de un riguroso estudio teórico y también empírico. No se pretende que de manera improvisada el legislador/constituyente disponga una lista más o menos acertada de las posibles fuentes del derecho que puedan resultar válidas o eficaces en y para nuestro ordenamiento jurídico, y las reconozca en una norma positiva, poniendo fin al dilema en cuestión.

De esta forma, de acuerdo a las corrientes más modernas, pudiera impulsarse un estudio multidisciplinar en el que se abarcaran aspectos culturales, psicológicos, sociológicos, organizacionales, entre otros tantos, que influirian decisivamente en el proceso de identificación de modos de creación jurídica diferentes al acto normativo. ${ }^{10}$

9 Sobre la categoría imperio de la ley, y algunos puntos críticos, Cfr., Hierro, Liborio L., "El imperio de la ley y la crisis de la ley", Doxa. Cuadernos de Filosofía del Derecho, núm. 19, 1996, pp. 287-308; Laporta, Francisco J., "Imperio de la ley. Reflexiones sobre un punto de partida de Elías Díaz", Doxa. Cuadernos de Filosofía del Derecho, núms. 15-16, 1994, pp. 133-145; McCormick, Neil, "Orden espontáneo e imperio de la ley: algunos problemas”, Doxa. Cuadernos de Filosofía del Derecho, núm. 6, 1989, pp. 309-327.

10 Interesan específicamente a esta propuesta corrientes de la teoría y filosofia jurídicas contemporáneas que han ponderado el valor del dere- 


\section{LA JURISPRUDENCIA COMO FUENTE DEL ORDENAMIENTO CUBANO}

En este particular es válido citar una expresión utilizada por el profesor Vilajosana, siguiendo criterios de H. L. A. Hart: "La actitud de la población y de los tribunales es de la mayor importancia para decidir la identidad y unidad de un orden jurídico", 11 aspecto que pudiéramos perfectamente asociar al tema debatido, pues un elemento clave en la identificación del ordenamiento jurídico descansa precisamente en la definición de sus fuentes.

La fijación de presupuestos para el reconocimiento de los modos de creación del derecho constituiría un paso intermedio, igualmente necesario. Aunque hablamos de una ruptura de paradigmas conceptuales, es lógico que la aceptación de nuevas formas se produzca de una manera tal que no implique el desmontaje del sistema, la alienación de

cho de origen judicial, contra la visión tradicionalista del derecho legislado, típico del sistema continental. A tales efectos merece la pena destacar teorías como la del activismo judicial, el derecho y la jurisprudencia vivientes, o el Nuevo derecho, que si bien retoman argumentos fundamentalmente de elaboraciones doctrinales y de prácticas del derecho anglosajón (v. gr., del realismo jurídico norteamericano, la sociological jurisprudence o los critical legal studies), introducen al mismo tiempo argumentos de una iusteoría local, representativa de un profundo anti-formalismo. A modo de ejemplo pueden citarse las obras del profesor López Medina (El derecho de los jueces (10 ma. reimpr.), Bogotá, Legis, 2011 y Teoría impura del derecho. La transformación de la cultura jurídica latinoamericana (7ma. reimpr.), Bogotá, Legis, 2013). Otros autores han contribuido a este debate (i. e., Maraniello, Patricio, "El activismo judicial, una herramienta de protección constitucional", Pensar en Derecho, núm. 1, 2012, pp. 121-165; Teixeira, Anderson, "Ativismo judicial: nos limites entre racionalidade jurídica e decisão política", Revista Direito GV, vol. 8, núm. 1, 2012, pp. 37-57; Carbonell, Miguel, "La Constitución viviente", Isonomía, núm. 35, octubre 2011, pp. 187-193; id., "Sobre la Constitución viviente", Revista Facultad de Derecho y Ciencias Politicas, Universidad Pontificia Bolivariana de Medellín, vol. 42, núm. 117, 2012, pp. 347-357; García Jaramillo, Leonardo, "El "Nuevo derecho" en Colombia: ¿entelequia innecesaria o novedad pertinente", Revista de Derecho de Barranquilla, núm. 29, 2008, pp. 289-330).

11 Vilajosana, Josep, El significado politico del derecho, México, Fontamara, 2005, p. 61. 


\section{CARLOS JUSTO BRUZÓN VILTRES}

un patrón cultural y la imposición de una práctica que resulte diametralmente opuesta a la que ha venido predominando. En otras palabras, para no ocultar con fraseología la verdadera dimensión del fenómeno, esta ruptura debe operarse sobre la base de la atención y no de la destrucción del modelo vigente.

Sin ánimo de anticiparme y negar con ello la necesidad de un estudio teórico y empírico de rigor, en algunas de estas manifestaciones de creación jurídica que hoy podemos identificar en la práctica del derecho en Cuba - y que, por ende, tienen su reflejo en una corriente de pensamiento más plural en la doctrina nacional, como examinaremos luego-, confluye un presupuesto común: El no desplazamiento del acto normativo como fuente de especial trascendencia del ordenamiento jurídico. Considérese acto normativo a la fuente legislada por excelencia, concepción que podemos matizar a partir de la materialización de la noción de Constitución como fuente de fuentes - abandonada de algún modo en nuestro contexto-. 12

Otro presupuesto común bien pudiera estar orientado hacia el rol que desempeñarian estas formas de creación jurídica por reconocer: El coadyuvar a la sistematización e integración del ordenamiento jurídico en su conjunto y a la minimización de los problemas que lo afectan, precisamente por la carencia de una visión sistémica en las circunstancias actuales. ${ }^{13}$

Los presupuestos, en definitiva, pudieran operar a modo de condiciones o requisitos, que aseguraran una recepción

12 Un análisis sobre los problemas de aplicabilidad y supremacía de la Constitución, con trascendencia a la ordenación de las fuentes del Derecho en Cuba, puede revisarse en: Prieto Valdés, Martha, "En pos de la aplicabilidad directa de la Constitución cubana de 1976 (un breve comentario)", Ius. Revista del Instituto Jurídico de Puebla, núm. 21, 2008, pp. 193-205.

13 Como se enfatizará en desarrollos posteriores del artículo, en esta visión general se incluye a la jurisprudencia, cuya utilidad y necesidad puede perfectamente delinearse de esta conclusión. 
y aplicación efectiva de las nuevas fuentes de derecho reconocidas por el legislador/constituyente.

Cierra este esquema lógico el reconocimiento de las fuentes del derecho en el ordenamiento positivo. Reconocimiento que, como tendré ocasión de exponer en relación a la jurisprudencia, debe ser preferiblemente realizado en el texto de la Constitución.

Existirian puntos de contacto notables en el cierre de este ciclo con la noción de regla de reconocimiento propuesta por Hart. ${ }^{14}$ Esta, tal como ha sido formulada por el autor e independientemente de las diversas interpreta- ciones a la que ha sido sometida, también ofrece opor- tunidades para la solución de la problemática general identificada en el presente estudio.

En tal sentido, en una de las investigaciones de mayor rigor científico sobre el tema realizadas en Cuba hasta la fecha, ${ }^{15}$ el profesor Walter Mondelo reconoce la utilidad del modelo hartiano, matizado y ampliado por las posiciones de

14 De la formulación original de la regla de reconocimiento ( $c f r$., entre otros pasajes, en Hart, H. L. A., El concepto de derecho, trad. de G. Carrió, Buenos Aires, Abeledo Perrot, 1963, pp. 125 y ss.), la interpretación más extendida entre nosotros está asociada a que esta regla permite identificar qué normas pertenecen al sistema, cuáles son legítimas, brindando certeza y validez de contenido a las normas primarias (Fernández Bulté, Julio, Teoría del Estado y del derecho, La Habana, Félix Varela, 2004, t. II, pp. 113 y 114). Como comento en este espacio, la investigación del profesor Mondelo intenta sistematizar dicha regla en el ordenamiento jurídico, aunque el debate teórico foráneo en torno a su formulación rebase los límites allí explicados. Es por ello que, a los efectos de la identificación del Derecho (un problema teórico de escaso tratamiento en Cuba), suscribo lo expresado por el propio Hart en su Post scríptum..., al considerar que "la existencia y contenido del derecho puede ser identificado por referencia a las fuentes sociales del derecho (e. g., legislación, resoluciones judiciales, costumbre social)" (Hart, H. L. A., Post scriptum al concepto del derecho, ed. por P. Bulloch y J. Raz, México, UNAM, 2000, p. 51).

15 Mondelo, Walter, Ordenamiento jurídico, Constitución y regla de reconocimiento, tesis en opción al grado de doctor en Ciencias Jurídicas, Santiago de Cuba, 2003. 


\section{CARLOS JUSTO BRUZÓN VILTRES}

Dworkin ${ }^{16}$ y Häberle, ${ }^{17}$ sobre la base de configurar una regla de reconocimiento que permita, en primera instancia, identificar el derecho válido y además, criticar las conductas que supongan una desviación del mismo. Esta regla debe contener al mismo tiempo elementos valorativos y arrancar necesariamente de la comprensión del carácter supremo (supremacía esencialmente normativa) de la Constitución, una tarea aún pendiente en nuestro ordena- miento.

$\mathrm{El}$ autor ofrece una formulación bastante general de esta regla, que puede servir también de base a los propósitos del reconocimiento de las fuentes del derecho en Cuba, ${ }^{18}$ aunque, a mi juicio, en este ámbito, debería ser más específico el alcance de aquella hipotética formulación. ${ }^{19}$

16 Dworkin, Ronald, Los derechos en serio, Barcelona, Ariel, 1984.

17 Häberle, Peter, El Estado constitucional, México, UNAM, 2001.

18 En una de las conclusiones de la investigación citada queda redactada esta propuesta como sigue: "En Cuba son válidas y deben ser obedecidas las normas jurídicas que, emitidas por las autoridades facultadas, no contradigan la Constitución y persigan la defensa de la Revolución". Inferimos que este enunciado deba situarse en el propio texto constitucional.

19 Es en este punto donde se precisa enunciar cuáles serían esas normas "válidas", que "deben ser obedecidas", al ser dictadas por "autoridades facultadas", según la cita supra, en fin, las fuentes del Derecho. Aquí pudiera quedar perfectamente delineada, en un sentido más específico, la regla de reconocimiento en las condiciones del ordenamiento jurídico cubano, que no debe entenderse solo como una formulación dentro del texto constitucional, ni la Constitución misma, aunque resulta posible que en la norma fundamental esté expresada parte de aquella regla. En consecuencia, cabe relacionar aquí el propósito de la regla de reconocimiento como criterio de identificación, con las propias "fuentes sociales" del derecho, en los términos empleados por Hart en su Post scriptum..., por lo que tanto la legislación como la jurisprudencia, pudieran operar así. La diferencia estriba en que la primera está reconocida positivamente -y perfectamente dirimida su validez-, mientras que la segunda, en su sentido de fuente, no, independientemente del criterio a contrario (punto de vista interno) sostenido en una parte considerable de los operadores jurídicos (cuyos ejemplos se muestran más adelante).Conviene afirmar finalmente que la delimitación en el ordenamiento interno de sus fuentes formales es parte indispensable de la definición de la regla de reconocimiento, y que el 
Este libro forma parte del acervo de la Biblioteca Jurídica Virtual del Instituto de Investigaciones Jurídicas de la UNAM www.juridicas.unam.mx

\section{LA JURISPRUDENCIA COMO FUENTE DEL ORDENAMIENTO CUBANO}

\section{Posiciones DOCTRINALES INTERNAS EN TORNO \\ A LA DETERMINACIÓN DE LAS FUENTES DEL DERECHO \\ Y DE LA JURISPRUDENCIA EN PARTICULAR}

\section{Puede afirmarse que en Cuba, en la etapa revolucionaria,} no se ha logrado construir una auténtica y específica teoría sobre las fuentes del ordenamiento jurídico. ${ }^{20} \mathrm{Un}$ argumento válido en torno a esta realidad se sostiene a partir del he-

instrumento normativo aquí defendido para establecer ese reconocimiento es la Constitución.

20 En perspectiva comparada, el debate sobre las fuentes del derecho ha seguido en Cuba una línea muy similar a la de la doctrina extranjera, especialmente de corte continental, predominantemente tradicionalista. Sin embargo, a diferencia de las limitaciones de la teoría continental (que en un discurso bastante uniforme pondera el papel de la ley como fuente esencial y solo, más reciente en el tiempo, rescata el valor de la Constitución como fuente de fuentes), el "tradicionalismo de fuentes" — siguiendo la expresión del profesor López Medina- en Cuba ha sido conceptualmente más estrecho. No alcanza incluso a explicar la jerarquía de fuentes, preservando la preeminencia de la Constitución y la ley, y situando por debajo de ellas otras como los principios generales, la costumbre o la jurisprudencia, sino que toda la construcción piramidal que se hace sobre estas se limita a las distintas manifestaciones del acto normativo. Si un recurso sirviera para desmontar este modelo formalista en extremo, sería - además de asumir el material explicativo valioso aportado por autores clásicos mencionados a lo largo del estudio: Aguiló, Legaz y Lacambra, Pérez Royo, inter alia- defender un enfoque anti-tradicionalista sobre las fuentes que implique, como consideran algunos teóricos contemporáneos, atacar el verticalismo dominante a partir de una noción de horizontalidad, circularidad, "no-piramidal" del mapa de fuentes. Ello, sin que signifique el abandono de algunos principios de ordenación claves como el de jerarquía normativa. Esta, del actual debate teórico sobre las fuentes, es la arista que más interesa al estudio en desarrollo. Cfr., González Jácome, Jorge, "El problema de las fuentes del derecho: una perspectiva desde la argumentación jurídica”, Vniversitas, núm. 112, 2006, pp. 265-293; Bernal Cano, Natalia, "El poder creador del juez en la combinación o mezcla de los procedimientos constitucionales", Estudios Socio-Juridicos Bogotá, vol. 12, núm. 1, 2010, pp. 11-34; López Medina, Diego, El derecho..., op. cit., pp. 268-269; Crisafulli, Vezio, “Jerarquía y competencia en el sistema constitucional de las fuentes", Revista de Derecho Constitucional Europeo, núm. 1, 2004, pp. 323-353. 


\section{CARLOS JUSTO BRUZÓN VILTRES}

cho comentado con anterioridad en relación al copismo prevaleciente en las primeras décadas de la Revolución y que, desafortunadamente, ha dejado conse- cuencias visibles hasta nuestros dias, tanto en la teoría como en la praxis jurídica.

Esta sería acaso una parcela de un problema mayor que describe el profesor Mondelo en uno de sus artículos. Como señala éste, la cuestión del derecho y la institucionalidad "Es uno de los asuntos menos tratados desde los propios orígenes del pensamiento socialista", ${ }^{21}$, conduciendo a la inexistencia de una teoría marxista del derecho, que se refleja en Cuba a partir de los efectos de un dilatado periodo de provisionalidad (1959-1976), que conllevó a "una cierta subestimación del papel del derecho en la sociedad, de la legalidad y del carácter de norma suprema de la Constitución". ${ }^{22}$

Por tanto, en relación al estudio de las fuentes del derecho $-\mathrm{y}$ de la jurisprudencia específicamente-, si bien no puede decirse que ha estado ausente del panorama doctrinal cubano, lo cierto es que revistió matices de poca creatividad y elevados niveles de asimilación de una teoría foránea que se asumió como propia (esencialmente proveniente del extinto campo socialista), ${ }^{23}$ en una primera etapa. Salvo contadas excepciones -i.e., el profesor Álvarez Tabí-, los autores más reconocidos en la enseñanza de la Teoría del derecho, el derecho constitucional y otras disciplinas jurídicas se hicieron eco de la existencia como única fuente del acto normativo y manejaron un discurso más o menos homogéneo en cuanto al desconocimiento de otro modo de

21 Mondelo, Walter, "Partir", op. cit., p. 119.

22 Idem.

23 A pesar de las necesarias críticas que se han realizado a la doctrina socialista resultaría poco honesto negar las contribuciones que en algunas materias hizo el Derecho soviético (y del campo socialista en general), enriqueciendo varias instituciones civiles, penales, internacio- nalistas, etcétera. 
producción jurídica que no fuera la ley, en su sentido genérico. $^{24}$

Asistimos actualmente, sin embargo, a un replanteamiento de estas posiciones. De esta manera, independientemente de que no se logra trazar una línea uniforme en cuanto al reconocimiento de las fuentes en nuestro ordenamiento jurídico, resulta más plural dicho análisis. Autores como Prieto Valdés, Mendoza Díaz, Matilla Correa, Rodríguez Sánchez y Pérez Carrillo - cuyas obras serán citadas a lo largo del artículo- dedican importantes espacios al abordaje de las fuentes, mostrando útiles comentarios respecto al reconocimiento del valor de la jurisprudencia, los principios generales, los tratados internacionales y otras manifestaciones de producción del derecho.

De igual forma en algunas investigaciones doctorales ${ }^{25}$ de la última década se introducen temáticas de un profundo matiz teórico, con aportaciones idénticamente relevantes en relación al tema de las fuentes del derecho. Sectorialmente varias disciplinas jurídicas inician sus respectivos estudios planteando las fuentes específicas de cada rama del derecho, con remisiones en la mayor parte de los casos al derecho comparado.

24 Cfr., a modo de ejemplo, Cañizares, Fernando D., Teoría del Estado, La Habana, Pueblo y Educación, 1979; Garcini, Héctor, Derecho administrativo, La Habana, Pueblo y Educación, 1986 y Grillo Longoria, Rafael, Derecho procesal civil. Teoría general del proceso, La Habana, Pueblo y Educación, 1993, t. I.

25 Cfr., Mondelo, Walter, Ordenamiento..., cit.; Prieto Valdés, Martha, El derecho, la Constitución y su interpretación, tesis en opción al grado de doctor en Ciencias Jurídicas, La Habana, 2002; Méndez López, Josefina, El modelo de creación de leyes en Cuba, tesis en opción al título de doctor en Ciencias Jurídicas, Santiago de Cuba, 1999; Carrillo, Yoel, El proceso legislativo en Cuba. Un modelo para su análisis, tesis en opción al título de Doctor en Ciencias Jurídicas, Santiago de Cuba, 2008; Ferrari Yaunner, Majela, Los principios de legalidad y seguridad juridica como fundamentos del proceso de integración del Derecho para colmar las lagunas de la ley en Cuba, tesis en opción al grado de doctor en Ciencias Jurídicas, La Habana, 2010. 
Esta realidad, insisto, no ha permitido fraguar una auténtica concepción en torno a la explicación/funda- mentación de los modos de creación jurídica en nuestro ordenamiento. ${ }^{26}$

Ahora bien, un análisis de esta naturaleza debe implicar un mínimo de fundamento empírico, por lo que es factible precisar que algunos resultados derivados de indagaciones científicas (más generales en unos casos, más particulares en otros), demuestran una apertura hacia el reconocimiento de fuentes distintas al acto normativo, entre las que se incluye la jurisprudencia. ${ }^{27}$

26 Que han limitado además la visión de las fuentes a su estricto significado de modos de producción del derecho, descuidando su importancia también como criterios de identificación y de validez del ordenamiento jurídico.

27 En la investigación de la profesora Ferrari Yaunner, relacionada con el problema de las lagunas en el ordenamiento jurídico cubano, ante la pregunta de qué vías emplearía para la "creación de una nueva norma que oriente cómo solucionar las lagunas" (Anexo 5), de la muestra encuestada -159 jueces, incluidos casi la totalidad de los magistrados del Tribunal Supremo-, el 84 \% se inclinó hacia la aplicación de los principios generales del derecho; el $50 \%$ optó por la equidad; el $47 \%$ por la jurisprudencia y el $40 \%$ por la analogía. Solo el $10 \%$ se decidió por aplicar reglas derivadas de la costumbre jurídica. En una pregunta posterior (en la que solo podía elegirse una opción), acerca de cuál sería la disposición normativa donde ubicaría la regulación de estos modos, el $49 \%$ de los encuestados (mayoría) opinó que debía ser en la Constitución de la República. Con una muestra más heterogénea - 37 profesionales del derecho, de ellos 20 jueces y el resto profesores universitarios y consultores - en una investigación pudiésemos decir más "local", el autor obtuvo resultados de interés. De ellos uno de los más sobresalientes tiene que ver con las "fuentes que deben ser reconocidas en el ordenamiento jurídico cubano". E1 59.4\% de los consultados se inclinó por la jurisprudencia (y un 27\% además por las sentencias particulares). Cfr. Bruzón Viltres, Carlos Justo, “Jurisprudencia en Cuba: análisis de las consecuencias de su reconocimiento como fuente formal del ordenamiento jurídico", Opinión Jurídica, Medellín, vol. 12, núm. 23, 2013, pp. 167-186. Estos datos demuestran que es un hecho el reconocimiento de la jurisprudencia y de otras fuentes en la práctica, aunque resulta más difícil asumir que existe pleno dominio en entre los operadores jurídicos de las formas concretas que revisten estas y de sus presupuestos de identificación.

\section{PROBLEMA}

Anuario de Filosofía y Teoria del Derecho, Núm. 9, enero-diciembre de 2015, pp. 279-325 
Estas aproximaciones al controvertido tema del reconocimiento de las fuentes de nuestro ordenamiento jurídico sirven, a la par de distinguir la variedad de posiciones al respecto, también para enfocar el debate en torno a la jurisprudencia, aspecto central del presente estudio.

Las lecturas en relación a las manifestaciones jurisprudenciales en el sistema de derecho de base romano- francesa no han tenido un desarrollo uniforme. Lo que ha quedado relativamente delimitado es su distinción con la formación de precedentes, que resulta la fuente por excelencia del derecho anglosajón. En tal sentido suelen identificarse como expresiones de la jurisprudencia en nuestro sistema la reiteración de fallos del máximo órgano de justicia (comúnmente identificada esta forma como doctrina legal o jurisprudencial, sin que, por su propio contenido podamos asimilar ambas instituciones como lo mismo) ${ }^{28}$ y las disposiciones emanadas de los tribunales superiores, obligatorias para el resto del sistema de tribunales, que develan una especie de potestas normandi expresada a través de diversas disposiciones normativas de carácter interno, que sujetan a recurso de casación su no observancia.

Estas y otras formas de creación judicial del derecho en el sistema continental - tal como sucede en Cuba- no han tenido una plena aceptación; aspecto que va resultando bastante común en las discusiones teóricas y que no es privativo de nuestras formaciones jurídicas. ${ }^{29}$ En esa direc-

28 Vallet de Goytisolo, Juan, "El razonamiento judicial", Anales. Real Academia de Jurisprudencia y Legislación, 39, Madrid, Dykinson S.L., 2009, pp. 19-32.

29 El profesor Brian Bix recrea un pasaje de Jeremy Bentham, a quien califica como un "apasionado detractor de la legislación de los jueces y de la toma de decisiones en el common law" que constituye, a mi juicio, un claro ejemplo de cómo esta controversia en torno al reconocimiento del valor de la creación judicial del Derecho se encuentra reñida incluso en la propia cuna de esta manifestación de producción jurídica. Afirmaba Bentham: "Son los jueces...los que hacen el common law. ¿Sabe cómo lo hacen? Como el hombre que legisla para su perro. Cuando el perro hace algo que no quieres que haga más, esperas a que lo haga y entonces lo re- 


\section{CARLOS JUSTO BRUZÓN VILTRES}

ción, pudiera ser interminable la lista de ejemplos que muestran las contradicciones en torno a la aceptación de los modos de creación judicial del derecho, situación que se agudiza en los ordenamientos de base continental. ${ }^{30}$

Sin embargo, se ha producido una relativización de posiciones en torno a la identificación de los modos de producción jurídica, que abre paso al reconocimiento del derecho de origen jurisprudencial. De ahí que, como ha dicho Lafuente Balle, incluso la tradicional distinción del derecho continental como un "derecho legislado", respecto al dere-

prendes. Así es como legislamos a los perros, tal como los jueces crean derecho para ti y para mí" (cfr., Bentham, Jeremy, "Truth versus Ashhurst", The Works of Jeremy Bentham, Edinburgo, W. Tait, 1843, vol. V, p. 235, cit. pos. Bix, Brian, Filosofía del derecho: ubicación de los problemas en su contexto, trad. de Imer Flores, Rodrigo Ortiz y Juan Vega Gómez, México, UNAM, 2010, p. 183). Recientemente Paul Yowell ha manifestado que considerar "a los jueces como legisladores desafía directamente la noción de Estado de derecho, y que los valores de la irretroactividad de la ley, promulgación y claridad no pueden ser satisfactoriamente logrados sin la separación institucional de las funciones legislativa y judicial". En consecuencia, la actividad creadora del juez del common law siempre debe estar situada en un plano de inferioridad respecto a la producción jurídica que se deriva de la actividad de los parlamentos. La obligación de estos de aplicar el derecho en un caso concreto, concluye, está en permanente tensión con su obligación de producir derecho: se mueven en direcciones opuestas (Yowell, Paul, "Legislación, common law y la virtud de la claridad", Revista Chilena de Derecho, vol. 39, núm. 2, 2012, pp. 481-512).

${ }^{30}$ Un ejemplo de la tajante oposición al carácter de fuente que se le atribuye a la jurisprudencia lo ofrece el profesor Manuel Albaladejo. En uno de los fragmentos de su clásico texto de Derecho Civil, interroga: “¿Es la jurisprudencia fuente del derecho?", y de modo inmediato afirma: "La respuesta es sencilla e indudable: no lo es". El argumento explícito: "puesto que la función de la fuente jurídica es crear normas, y la jurisprudencia no las crea, es claro que no es fuente". Vid., Albaladejo, Manuel, Derecho civil (introducción y parte general), 15a. ed., Barcelona, Librería Bosch, 2002, t. I, p. 139. 
cho anglosajón como un "derecho jurisprudencial basado en el precedente", haya "perdido virtualidad". 31

Partiendo de este hecho, afirma el profesor Atienza que los jueces son importantes agentes de cambio jurídico, "tanto en los sistemas de common law como en los sistemas de derecho codificado",32 pudiendo cumplir esta función porque "en contra de lo sostenido por la doctrina jurídica tradicional crean en muchas ocasiones derecho, son fuentes del derecho". 33

En Cuba el panorama doctrinal en relación al tema objeto de debate se ha mostrado igualmente contradictorio.

Cañizares, por ejemplo, ha afirmado que "La jurisprudencia como fuente de derecho es inadmisible dentro del sistema jurídico socialista, por cuanto en un régimen de estricta legali-

31 Cfr. Lafuente Balle, José Ma., La judicialización de la interpretación constitucional, Madrid, Colex, 2000, p. 51. Este autor parte del papel de la jurisdicción constitucional, especialmente en Europa, en la formación de lo que llanamente denomina precedentes, aunque no es, sin dudas, el único centro de impulsión de esta relativización en nuestro sistema jurídico. Por otro lado también se verifica en la práctica actual - y no tan actual- una tendencia a la proliferación legislativa en algunas áreas del derecho anglosajón, hecho que contribuye a confirmar esta conclusión (en Estados Unidos es lo que sucede, i. e., respecto al denominado Administrative law. Señalan David y Jauffret-Spinosi que "en la actualidad existe una proliferación de leyes considerable" en este país, leyes que si bien deben ser interpretadas y aplicadas por los tribunales, contribuyen al "conocimiento del derecho" por parte de ciudadanos y juristas, al tiempo que implican cierto "riesgo de alterar la uniformidad del common law" (cfr., David, René y Camille Jauffret-Spinosi, Los grandes sistemas jurídicos contemporáneos, trad. de Jorge Sánchez Cordero, México, UNAM, 2010, pp. 305-328). Más de una veintena de Estados de la Unión posee leyes de procedimiento y otras disposiciones legales en diversas materias, que no deben, técnicamente, confundirse con la codificación continental, aunque como reconocen los autores "en un momento determinado de su historia se consideró la adopción de una codificación de corte napoleónico" (p. 325).

32 Atienza, M., Introducción al derecho, México, Fontamara, 1998, p. 79.

33 Idem. 
dad como este, tanto los órganos judiciales como administrativos deben aplicar el derecho y no crearlo". ${ }^{34}$

Un procesalista de la talla de Grillo Longoria, compartiendo época con el mencionado profesor Cañizares, negó la existencia de la jurisprudencia como fuente porque este hecho significaba "Otorgarle a los tribunales una función legislativa que no les concierne". ${ }^{35}$ Creo que una de las pocas excepciones -entre los autores que podemos denominar "clásicos" en el terreno doctrinal cubano- fue la del mencionado profesor Álvarez Tabío, pionero en la identificación del papel del Consejo de Consejo de Gobierno del Tribunal Supremo como órgano creador de jurisprudencia. Las interpretaciones que este realiza, estima este autor, "Se convierten en juicios de derecho, de rango equivalente a la norma legal, cuya contradicción, oscuridad u omisión vienen a subsanar". 36

Con un pequeño margen de flexibilidad, que apunta sobre todo al reconocimiento del papel de las decisiones de este órgano de gobierno del Tribunal Supremo Popular y los efectos que produce su inobservancia (en particular la casación), pero sin admitir el valor de fuente formal de las mismas en aquellos casos en que efectivamente contri- buyen a colmar vacíos o resolver contradicciones norma- tivas, se ubican también las opiniones de importantes exponentes de la doctrina jurídica cubana como Fernández Bulté y Pérez Gallardo. ${ }^{37}$

En una línea relativamente opuesta se sitúan otros autores, que han coadyuvado a ampliar el debate tanto en torno a las fuentes del ordenamiento jurídico cubano, como de la jurisprudencia específicamente. Mencionaré, a los efectos

34 Cañizares, Fernando D., op. cit., p. 80.

35 Grillo Longoria, Rafael, op. cit., p. 17.

36 Álvarez Tabío, Fernando, El recurso de inconstitucionalidad, La Habana, Editorial Libreria Martí, [s/f], p. 383.

37 Cfr., Fernández Bulté, J., op. cit.; Pérez Gallardo, Leonardo, "Introducción al derecho civil", en Valdés, Caridad et al., Compendio de derecho civil, La Habana, Félix Varela, 2007, pp. 100-127. 
de ubicar sus principales pronunciamientos, algunos de los ejemplos que también se han referido con anterioridad.

Para la profesora Prieto Valdés, ${ }^{38}$ i. e., la jurisprudencia debe tener un lugar dentro del sistema de fuentes de nuestro ordenamiento, si bien de carácter supletorio respecto a la ley. Mendoza Diaz afirma que, a partir del enunciado contenido en el artículo 630.1 de la Ley de Procedimiento Civil, Administrativo, Laboral y Económico, 39 "Se ha elevado a la categoría de fuentes formales del ordenamiento civil en general, y del derecho procesal en particular, los criterios interpretativos (...) del Consejo de Gobierno del Tribunal Supremo". ${ }^{40}$ Rodríguez Sánchez, analizando el valor de la jurisprudencia en sede penal, concluye: "La jurisprudencia desempeña un importante papel en la solución de la amplia variedad de casos y problemas (...) se impone asimilar cierta actividad de creación por parte del juez (...) sin que ello implique atribuir al juez la facultad de legislar". ${ }^{41}$

Concentrado también en la trascendencia de los pronunciamientos del órgano de gobierno del Tribunal Supremo

38 Prieto Valdés, Martha, El derecho..., op. cit., p. 89.

39 "Artículo 630.- Procede el recurso de casación por los motivos siguientes:

1.-Que la sentencia o resolución contenga infracción por falta de aplicación, interpretación errónea o aplicación indebida, con trascendencia al fallo, de las leyes, de las interpretaciones de estas emanadas del Consejo de Estado, de las instrucciones de carácter obligatorio dictadas por el Pleno del Tribunal Supremo Popular o su Consejo de Gobierno, recogiendo la experiencia de la actividad judicial en la interpretación y aplicación de las leyes, o de las decisiones dictadas por esos órganos al evacuar consultas de los tribunales sobre conflictos entre leyes y otras disposiciones de rango normativo inferior."

40 Mendoza Díaz, Juan, et al., Lecciones de derecho procesal civil, La Habana, Félix Varela, 2001, p. 18.

41 Rodríguez Sánchez, Ciro F. y Hernández, R., "La jurisprudencia como fuente complementaria del Derecho", Memorias de la IV Conferencia Cientifica sobre el Derecho, Santiago de Cuba, Universidad de Oriente, 1997, p. 41. 
cubano, Matilla Correa ${ }^{42}$ confirma la importancia de reconocer esta peculiar forma de crear derecho. Le atribuye, no obstante, carácter de fuente material, cuestión que desde la postura defendida en este estudio no se comparte plenamente.

Estos son algunos de los criterios que nos permiten definir que tanto en torno a la determinación del sistema de fuentes del derecho en Cuba, como respecto a la jurisprudencia en particular, existen contradicciones y más importante aún, una carencia de regulación normativa con profundas consecuencias jurídicas. Justifica además este análisis la necesidad de partir de la identificación de estas manifestaciones de creación del derecho (primer paso del esquema lógico trazado), para proponer soluciones que conlleven a su reconocimiento formal.

\section{FIJACIÓN DE PRESUPUESTOS PARA EL RECONOCIMIENTO DE LA JURISPRUDENCIA COMO FUENTE FORMAL}

Antes de profundizar en la temática planteada considero oportuno citar esta aseveración del profesor Pérez Carrillo:

A la hora de dar cuenta - como juristas- de las fuentes del derecho que verdaderamente operan en la práctica jurídica de un país, así como para poder medir hasta qué punto aquellas fuentes se corresponden con las que declara o reconoce (expresa o implícitamente) el sistema jurídico, no es posible prescindir de la diferenciación entre fuentes formales y fuentes materiales del derecho. ${ }^{43}$

42 Matilla Correa, Andry, "Comentarios sobre las fuentes del Derecho Administrativo cubano (excepto el reglamento)", en Castanedo, A. et al., Temas de Derecho Administrativo cubano, La Habana, Félix Varela, 2006, pp. 33-219.

43 Pérez Carrillo, Juan R., op. cit., p. 321. 
Esta cita in extenso refleja otra polémica en el campo doctrinal cubano que afecta directamente al reconocimiento de la jurisprudencia, previa definición de sus presupuestos.

De tal manera, aunque las clasificaciones doctrinales en relación a las fuentes del derecho son diversas, ${ }^{44}$ asumiremos como par central este de fuentes materiales/fuentes formales, para intentar ubicar, en definitiva, a la jurisprudencia.

Fuentes formales serían aquellos modos de creación jurídica derivados de la actuación de autoridades facultadas (cum potestas normandi), mediante un determinado procedimiento o mecanismo que se encuentre debidamente reconocido en el ordenamiento jurídico. En la concepción de fuente formal deben intervenir ineludiblemente los criterios de reconocimiento, como de cambio $^{45}$ y adjudicación ${ }^{46}$, en un sentido análogo a lo postulado por Hart.

44 En nuestro escenario han irradiado algunas concepciones como las de "fuentes acto"/"fuentes hechos", y "fuentes fundamento"/"fuentes modo" (cfr., v. gr., Aguiló, Josep, Teoría general de las fuentes del derecho (y del orden jurídico), Barcelona, Ariel, 2000 y Legaz, Luis, Filosofía del derecho, Barcelona, Bosch, 1961). Otras denominaciones: fuentes primarias/secundarias; legales/extralegales; directas/indirectas; escritas/no escritas; de conocimiento, de autoridad creadora, etcétera ( $c f r$., también, Fernández Bulté, Julio, Teoría..., op. cit.).

45 De la noción original de regla de cambio en Hart, hemos aceptado durante décadas la interpretación de que estas hacen referencia a las normas que "establecen quiénes, cómo y cuándo se pueden cambiar las normas primarias sin alterar su legitimidad" (Fernández Bulté, Julio, Teoría..., cit., p. 114). Aunque en este tema existen algunas controversias, estas son relativamente amainadas en el punto en que se logra identificar a través de la letra constitucional la facultad de modificación o derogación de determinadas disposiciones normativas, en algunos órganos superiores de poder, i. e., la Asamblea Nacional o el Consejo de Estado (v. gr. artículo 75 b)-seguidamente, sin embargo, se genera una contradicción en cuanto al alcance de las disposiciones de ambos órganos, cuya explicación excedería los propósitos del artículo, aunque se mencionan más adelante algunas fuentes doctrinales de referencia-.

46 En cuanto a la regla de adjudicación, parece poder identificarse desde el artículo 120 constitucional, al establecer la facultad de, tomando una cita de Encarnación Fernández, "ciertos órganos para determinar si 


\section{CARLOS JUSTO BRUZÓN VILTRES}

No debemos perder de vista, al mismo tiempo, el carácter que da Raz a estas fuentes en su sentido formal: "Son las que establecen la validez del derecho". ${ }^{47}$

El profesor Fernández Bulté, uno de los íconos indiscutibles de la enseñanza del derecho en Cuba, respecto a las fuentes materiales exponia que debian identificarse como "Aquellas circunstancias materiales, objetivas, de las que emana el derecho (...) la fuente material del derecho es la sociedad viva (...) de la vida misma sale el derecho". ${ }^{48}$

Convergiendo con esta noción de fuente material en algunos puntos, aunque tal vez su orientación no sea centralmente marxista, es válido mencionar el enfoque brindado por la denominada "tesis de las fuentes sociales del derecho", que aplicada a un debate mucho más amplio en torno a la identificación y justificación del derecho, nos resulta muy útil para ubicar el presente análisis.

Moreso y Vilajosana, por ejemplo, resumen que "La existencia y contenido del derecho en una sociedad dependen

en una ocasión particular se ha transgredido o no una regla primaria" (Fernández, Encarnación, "Derecho y otros órdenes normativos", en De Lucas, Javier (ed.), Introducción a la Teoría del derecho, La Habana, Ed. Félix Varela, 2006, p. 145). Estos órganos están encabezados por el Tribunal Supremo Popular, quien ejerce a nombre del pueblo la función de impartir justicia. Precisamente su Consejo de Gobierno es uno de los agentes de formación de jurisprudencia como fuente que defiendo en este estudio. Esto sirve de marco para plantear la posible extensión de la regla de adjudicación en el ordenamiento cubano, en términos que favorezcan el reconocimiento de la producción jurídica en sede judicial, generada desde las instrucciones y demás disposiciones vinculantes emanadas del mencionado órgano de gobierno del Tribunal Supremo. Un número considerable de estas decisiones se adoptan por imperativo de la solución de controversias que, asumiendo la terminología de Dworkin, representan verdaderos casos difíciles en la práctica judicial cubana.

47 Raz, J., The Authority of Law, Oxford, Oxford University Press, 1979, p. 67 .

48 Fernández Bulté, Julio, Teoría..., op. cit., pp. 52 y 53. 
de un conjunto de hechos sociales, es decir, de un conjunto de acciones de los miembros de dicha sociedad". 49

Analizados diversos puntos de la tesis de las fuentes sociales del derecho (especialmente desde la postura teórica de $\mathrm{Raz}$, el profesor Vega Gómez apunta que "La tesis sostiene que lo que es derecho es una cuestión fáctica de hechos sociales, plenamente identificables sin recurrir a argumentos evaluativos". ${ }^{50}$ Así, sin que esto implique absolutamente despreciar elementos morales, se identifica al derecho desde presupuestos objetivos sin pretender explicar incluso sus límites desde la función interpretativa o jurisdiccional.

Sobre la base de estos criterios sostengo que la jurisprudencia más que fuente material, es formal, lo cual no desdice el necesario fundamento objetivo de las decisiones judiciales, porque estas se basan -y es un criterio sostenido en el foro jurídico- en la experiencia acumulada de la práctica, con una profunda influencia de las cambiantes circunstancias sociales.

$\mathrm{Su}$ formación, no obstante, implica un procedimiento, un modo particular de creación - que puede llegar a convertirse en creación jurídica-, impulsado por un órgano debidamente investido con esta facultad (el tribunal). De esta forma, aunque este último sea tal vez el punto más controvertido en la doctrina cubana a la hora de asimilar la jurisprudencia como fuente del derecho, tanto algunos de los criterios de otros autores, como los que se esbozan en el presente estudio, indican que reside en el Tribunal Supremo, y particularmente en su Consejo de Gobierno, una peculiar manifestación de potestas normandi, reconocida constitucional y legalmente.

En otro orden de ideas, se presenta la configuración conceptual de jurisprudencia. Como es conocido, esta institu-

49 Moreso, José J. y Josep M. Vilajosana, Introducción a la teoría del derecho, Madrid-Barcelona, Marcial Pons, 2004, p. 196.

50 Vega Gómez, Juan, "El positivismo excluyente de Raz", Boletín Mexicano de Derecho Comparado, vol. 37, núm. 110, 2004. 


\section{CARLOS JUSTO BRUZÓN VILTRES}

ción es tan antigua como el derecho mismo. ${ }^{51}$ No sería suficiente el espacio de este artículo para incorporar el análisis histórico y las definiciones respecto a esta categoria, tan vastas como las propias corrientes de la filosofia jurídica que se han formado en su entorno. Por tanto, entiendo a la jurisprudencia, en principio, como manifestación de la creación judicial del derecho.

De tal modo, el estudio de la jurisprudencia en Cuba se concentra en la actividad de sus órganos judiciales superiores y el papel que actualmente desempeñan en el proceso de integración y armonización de nuestro ordenamiento jurídico, que precisa plantear algunos de los presupuestos que pudieran contribuir al reconocimiento futuro de esta manifestación como modo de creación del derecho.

1. La jurisprudencia como fuente de derecho debe partir de la actividad del Tribunal Supremo Populary su Consejo de Gobierno, no de la creación individual del juez

Para no romper la lógica del esquema planteado, comenzaré por explicar este primer presupuesto. Entiéndase presu-

51 Se ha escrito mucho también sobre el origen y evolución de la jurisprudencia - considerando además su perspectiva de fuente- Han contribuido a la comprensión de este dilatado proceso algunos textos, inter alia: Tamayo y Salmorán, Rolando, "Jurisprudencia y formulación judicial del Derecho (Principium)”, Isonomia, núm. 21, 2004, pp. 193-215, id., Razonamiento y argumentación jurídica. El paradigma de la racionalidad y la ciencia del derecho, México, UNAM, 2003; Magallón Ibarra, Jorge M., La senda de la jurisprudencia romana, México, UNAM, 2000; id., Los sonidos y el silencio de la jurisprudencia mexicana, México, UNAM, 2004; id., El renacimiento medieval de la jurisprudencia romana, México, UNAM, 2002; Torres Zárate, Fermín, "La jurisprudencia (su evolución)”, Alegatos, núm. 72, 2009, pp. 151-176; Domingo, Rafael, "La jurisprudencia romana. Cuna del derecho", Anales de la Real Academia de Ciencias Morales y Políticas, vol. 81, núm. 2, 2004, pp. 371-393; López Medina, D. E., “Tres caminos históricos en la formación de la jurisprudencia en América Latina: Recepción y vicisitudes del concepto de "doctrina legal" en la región", en González, A. y Del Río, J. (comps.), Discusión jurídica contemporánea desde Michoacán, México, Tribunal Electoral del Estado de Michoacán, 2011. 
puesto, reitero, como condición o requisito para el reconocimiento posterior de una fuente del derecho o, en palabras de Kelsen, como un argumento fundacional implicado en esta categoría.

Debido a las propias características del derecho cubano, inscrito en el sistema continental, considero que el reconocimiento de la jurisprudencia debe partir de la identificación del rol del Tribunal Supremo y, particularmente, de su Consejo de Gobierno (en lo adelante, CGTSP) dentro del ordenamiento jurídico cubano y su trascendencia, como se ha apuntado con anterioridad, frente al proceso de integración y armonización de éste.

En efecto, la propia letra de la Constitución le confiere un importante papel al Tribunal Supremo Popular en Cuba, depositario de la función de administrar justicia a nombre del pueblo (artículo 120), como se ha comentado con anterioridad. En similar registro, establece respecto a su Consejo de Gobierno el ejercicio de la iniciativa legislativa, la potestad reglamentaria, la toma de decisiones y la facultad de dictar normas de obligatorio cumplimiento para todos los tribunales, además de que "Sobre la base de la experiencia de estos imparte instrucciones de carácter obligatorio para establecer una práctica judicial uniforme en la interpretación y aplicación de la ley". ${ }^{52}$

Ciertamente, en función de este mandato constitucional, puede apreciarse una actividad sostenida de este órgano para aportar soluciones jurídicas a aspectos claves dentro del proceso de actualización del modelo económico y social cubano, que exige obviamente un cambio esencial de sus bases jurídicas. Haciéndonos eco de las palabras del profesor Bix, en relación a similar postura de Hart, respecto a aquello de que la "Creación del derecho por parte del judicial tiene como fundamento el avanzar los propósitos de la

52 Constitución de la República de Cuba, artículo 121. 


\section{CARLOS JUSTO BRUZÓN VILTRES}

legislación",53 puede afirmarse que en la actualidad sucede algo similar con los pronunciamientos del CGTSP.

Es extensa la muestra que sostiene esta apreciación, vista desde sentencias, instrucciones, acuerdos, dictámenes $\mathrm{y}$ otras disposiciones internas de este órgano judicial. Un ejemplo bastante claro puede apreciarse a través de la Instrucción 215, de 13 de abril de 2012, mediante la cual se establece un proceder complementario a lo dispuesto en la Ley de Procedimiento Civil, Administrativo, Laboral y Económico, en materia de ejecución de títulos de crédito derivados de relaciones económico-contractuales.

Si bien las bases del proceso ejecutivo están definidas en aquella Ley, los elementos que la complementan, el alcance de sus términos, los sujetos a los que obliga y el carácter extensivo hacia la legislación civil que se le confiere, al tenor de esta Instrucción, convierten a la misma en la norma realmente observable en la solución de procesos de esta naturaleza. Se crea, sin dudas, una regla paralela, que no se limita a establecer nuevos cánones interpretativos, sino que supone la integración de una disposición cuyo uso inadecuado permitía considerar las insuficiencias mismas de la ley, ahora "colmadas" por esta Instrucción.

Otro ejemplo es la Instrucción 216, del 17 de mayo de 2012, que introduce elementos de significativa novedad para el proceso familiar en nuestro país. Dichas aportaciones, en sintesis, se orientan hacia el "Modo de proceder respecto a la comparecencia a que se contrae el artículo 42 de la Ley de Procedimiento Civil, Administrativo, Laboral y Económico; el momento en que procede el llamamiento al proceso de terceros con interés legítimo; el modo de proceder para la escucha del menor; la participación del Ministerio Fiscal en estos procesos; las previsiones que deben atenderse para la constitución y el funcionamiento en cada territorio del equipo multidisciplinario; la necesidad de mecanismos que aseguren el ulterior cumplimiento de las obligaciones declaradas

53 Bix, Brian, op. cit., p. 60. 
por resolución firme, mediante un sistema cautelar propio que incluya la actuación oficiosa de los tribunales y la solicitud a instancia de las partes involucradas, además de la posi- bilidad de adopción de tutelas urgentes, dada la connotación de los intereses que se protegen; y específicas previsiones para el caso de la ejecución forzosa de lo decidido en firme, para lo cual se debe partir de una visión integradora y armónica del ordenamiento vigente". ${ }^{54}$

No puede pretenderse, con tan variadas y complejas temáticas abordadas en esta disposición, que se trata solo de una instrucción de carácter obligatorio "para establecer una práctica judicial uniforme en la interpretación y aplicación de la ley", como se ha citado; se trata realmente de una nueva disposición normativa que opera como integradora de un vacío legislativo en torno a esta materia y que ha servido, indiscutiblemente, para actualizar y reforzar la tutela de una parte importante de las sensibles relaciones en el ámbito del derecho de Familia que se sustancian en sede procesal.

Hago énfasis en la necesidad de distinguir entre el reconocido carácter interpretativo que deben poseer los criterios del CGTSP, en relación con la norma que debe ser aplicada, frente al carácter verdaderamente innovador de sus soluciones. Al respecto parece muy ilustrativa esta opinión de Raz: "La interpretación del derecho puede ser tan creativa como una interpretación de Glen Gould de una sonata para piano de Beethoven". 55

Lo cierto es que la distinción entre interpretación y creación del derecho - cuyos frágiles limites continúan siendo objeto de un arduo debate entre los teóricos y operadores del derecho- también considera sus efectos y, en este caso, conviene afirmar que algunos de los pronunciamientos del CGTSP, obligatorios para el resto del sistema de tribunales,

54 Esta es la transcripción literal de una parte del Tercer Por Cuanto de la citada Instrucción.

55 Raz, Joseph, Ethics in the Public Domain, Oxford, Oxford University Press, 1994, p. 230, cit. pos., Vega Gómez, Juan, “El positivismo...”, op. cit. 
sobrepasan los marcos de la interpretación normativa, para crear nuevas reglas, en fin, producen derecho.

Es en esta dirección donde puede identificarse una manifestación clara y muy peculiar en el sistema continental, de creación judicial del derecho, de jurisprudencia como fuente formal. De otra manera, asumir que el juez individualmente crea normas juridicas, bien a través del fundamento de sus sentencias (ratio decidendi), o mediante la reiteración de fallos en caso análogos (nunca idénticos, nos queda claro), resultaría una proposición más riesgosa. Entraña cierto peligro pues puede desvirtuar la esencia misma del sistema orientándose más a un modelo de precedentes, típico del mundo anglosajón, aunque la relativización de estos conceptos - que hemos analizado antes - pudiera considerar a futuro esta opción.

\section{El no desplazamiento del acto normativo como fuente de especial relevancia dentro del ordenamiento juridico}

Un efectivo reconocimiento de la jurisprudencia en el sentido de creación del derecho no puede desconocer el valor otorgado al acto normativo como fuente de especial relevancia en nuestro ordenamiento jurídico. Cuestión esta que no ha estado exenta de dificultades, pero que ha obe- decido al profundo legalismo sobre el cual se ha diseñado el derecho socialista y, particularmente, el derecho cubano.

Esto, por ejemplo, ha traído visibles consecuencias en la concepción de la Constitución como fuente de fuentes, en su supremacía jurídica, y en la eficacia del principio de constitucionalidad. ${ }^{56}$

No obstante lo dicho, la propia Constitución reconoce a través de la facultad constituyente y legislativa otorgada a la Asamblea Nacional del Poder Popular (artículo 70 constitucional), y su carácter de órgano supremo de poder del Estado, la preponderancia de la ley, en sentido genérico,

56 Cfr. Prieto Valdés, Martha, "En pos...", op. cit. 
dentro del ordenamiento jurídico cubano. Podemos asumir, incluso, que aunque no se reconoce expresamente como fuente es, sin dudas, la única forma de creación jurídica válida en nuestro derecho.

Intentar reconocer una manifestación de producción normativa diferente en un plano de superioridad jerárquica respecto a la ley tendría muy poco fundamento en este contexto. Si acaso sirviera para algo, sería para reavivar los viejos -aún persistentes - temores en torno al gobierno de los jueces y la disminución de la calidad democrática del sistema, con la correspondiente afectación al principio de soberanía popular encarnado en los parlamentos del derecho continental.

Evidentemente, esta posición respecto al papel de la función judicial debe ser superada. Afirma De Vega en tal sentido que "La posible incidencia del Poder Judicial en la vida del Estado no pasa de ser un recurso ideológico que, por estar parcial e interesadamente empleado, le priva de todo fundamento (...) Acrecentar ahora su influencia, acaso fuera más compensar un tradicional desequilibrio histórico, que establecer ningún tipo de preeminencia". ${ }^{57}$

Sin embargo, no creo que las posturas dominantes hasta la actualidad pudieran ceder con relativa facilidad ante estos cambios propuestos. Tampoco la solución a los problemas descritos en este estudio descansa en invertir los términos que configuran nuestro sistema jurídico, con lo cual resultaría saludable y provechoso asumir el reconocimiento de la jurisprudencia partiendo como presupuesto de su carácter complementario, en relación al acto normativo, en su

57 De Vega, Pedro, Estudios político-constitucionales, México, UNAMUCM, 2004, p. 304. El profesor Fix-Zamudio ha contribuido también a enfrentar esta postura concluyendo que la fuerza de los órganos judiciales no se apoya en elementos de carácter material -como sí los tiene el Poder Ejecutivo-, sino en "su prestigio moral y su estricta imparcialidad" (cfr., Fix-Zamudio, Héctor, Veinticinco años de evolución de justicia constitucional, 1940-1965, México, UNAM, Instituto de Investigaciones Jurídicas, 1968, p. 16). 


\section{CARLOS JUSTO BRUZÓN VILTRES}

carácter de fuente tradicionalmente aceptada como fundamental en el ordenamiento jurídico cubano.

\section{No afectación del principio de legalidad y prohibición de actividad legislativa paralela}

En consonancia con lo planteado en el apartado anterior, el reconocimiento de la jurisprudencia como fuente debe atender además el valor que se le ha dado al principio de legalidad, como columna vertebral de nuestro sistema jurídico. No creo, en definitiva, que tal reconocimiento imponga desconocer el mencionado principio, por lo cual me interesaré más por explicar la segunda proposición implícita en este presupuesto.

Se trata, en esencia, de evitar una fragmentación de la facultad legislativa, que ha quedado delineada en el texto constitucional, a partir de reconocer como único órgano con potestad constituyente y legislativa a la Asamblea Nacional del Poder Popular (artículo 70). Lo cierto es que, en la práctica, aunque se confirma que el Consejo de Estado realiza una función legisferante cuyo resultado (disposiciones con carácter de decretos-leyes) se equipara al efecto de las leyes emanadas de la Asamblea, 58 no existen razones para aceptar que un órgano de naturaleza judicial asuma una función que técnica y legalmente no le corresponde.

El ejemplo del Consejo de Estado es solo un botón de muestra que apunta a una relativización de los limites competenciales para el ejercicio de la función legislativa, que desde el punto de vista técnico implica consecuencias sobre principios esenciales del ordenamiento como el de jerarquía normativa. Este hecho deriva también del vacío existente en

58 Muy polémico este punto en el debate doctrinal cubano. Reflexiones acerca del complejo papel asumido por el Consejo de Estado y el fundamento de la equiparación de los decretos leyes en relación con las leyes en el ordenamiento cubano en: Villabella, Carlos, Historia constitucional y poder político en Cuba, Camagüey, Ácana, 2009, pp. 105 y ss.; Méndez López, Josefina, Op. cit., pp. 85-86; Matilla Correa, Andry, en op. cit., pp. 66-71. 
torno a la determinación de los criterios de ordenación de las fuentes, lógicamente ausente de nuestro derecho positivo.

En resumen, la labor del CGTSP no debe implicar un desarrollo legislativo paralelo. Debe constreñirse a complementar oportunamente aquella función, resolviendo posibles lagunas o contradicciones que aparezcan en el tracto de las relaciones jurídicas sin que ello suponga desconocer el carácter innovador, creativo, de algunas de estas decisiones judiciales respecto al ordenamiento mismo.

\section{La jurisprudencia debe tener fines bien delimitados}

En aras de no redundar sobre algunos elementos que se han venido abordando a lo largo del artículo solo me limitaré a enunciar algunos de los fines que deben quedar explícitamente delimitados para asegurar un efectivo reconocimiento de la jurisprudencia en el derecho cubano, que confirman la importancia de este hecho - y la utilidad de lo defendido en este artículo-. Aunque fines y funciones son categorias que indican situaciones diferentes, en este caso corren la suerte de complementarse. Por esta razón resulta factible plantear, de manera muy general, algunas de las funciones atribuidas a la jurisprudencia, especialmente en el contexto del sistema de derecho romano-francés, que Matilla Correa define, grosso modo, de la siguiente manera: Explicativa, aclaratoria o interpretativa; complementadora; integradora, supletoria o subsidiaria; creadora; renovadora, actualizadora o correctora; unificadora; rectora; conciliadora y de equilibrio. 59

Considerando estos elementos puede concluirse que el reconocimiento de la jurisprudencia en nuestro ordenamiento jurídico debe ir orientado hacia los siguientes propósitos o fines: La ampliación del sistema de fuentes del ordenamiento jurídico cubano, contribuyendo a su armonización y funcionamiento sistémico; el reforzamiento de la actividad unifor-

59 Matilla Correa, Andry, en op. cit., pp. 99-104. 
madora en la interpretación y aplicación del derecho desde el órgano supremo de justicia y la creación de un mecanismo efectivo para la integración del derecho frente a la existencia de lagunas normativas, ${ }^{60}$ así como la solución de eventuales contradicciones normativas con la aplicación de los principios correspondientes.

\section{NECESIDAD DEL RECONOCIMIENTO CONSTITUCIONAL DE LA JURISPRUDENCIA COMO FUENTE FORMAL DEL ORDENAMIENTO JURÍDICO CUBANO}

Este, a mi juicio, debería configurarse como el primer presupuesto para el reconocimiento de esta fuente formal del derecho. Sin embargo, debido a que precisamente es el reconocimiento el paso que cierra el esquema lógico trazado, he preferido abordarlo, a grandes rasgos, en este epígrafe. No obstante, el emplear el término esquema para describir estos pasos o etapas en el reconocimiento de las fuentes, no indican que ignoremos el carácter de proceso que posee tal reconocimiento, "proceso de validación" como lo define Oscar Correas, para hacernos entender además que la cuestión de la existencia de las normas (que se entronca con los problemas de validez) "depende siempre de un discurso de reconocimiento". 61

Comúnmente la doctrina y la legislación atribuyen a la Constitución o al Código Civil el establecimiento de las fuentes del derecho. En este último caso, dada la naturaleza de

60 Es un hecho comprobado la existencia de lagunas normativas en nuestro ordenamiento jurídico. Además de la investigación de la profesora Ferrari Yaunner citada anteriormente pueden consultarse los siguientes estudios al respecto: Ferrari Yaunner, Majela, "Las lagunas jurídicas. Posiciones doctrinales y jusfilosóficas", Revista Cubana de Derecho, núm. 34, 2009, pp. 45-68; Galiano, Grisel y Deyli González, "La integración del derecho ante las lagunas de la ley. Necesidad ineludible en pos de lograr una adecuada aplicación del derecho", Díkaion. Revista de Fundamentación Jurídica, vol. 21, núm. 2, 2012.

61 Correas, Óscar, Teoría del derecho, México, Fontamara, 2010, p. 88. 
derecho común supletorio que posee respecto al resto de las ramas del ordenamiento jurídico. No obstante, partiendo del análisis que se introdujo en torno al valor de la regla de reconocimiento, perfectamente aplicable en nuestras condiciones, considero que la regulación del sistema de fuentes debe operar en el texto constitucional (pues en este, se ha dicho, puede estar expresada parte de aquella regla, en el momento mismo en que dichas fuentes son reconocidas).

Con absoluta claridad varios autores han definido que es la Constitución la "norma delimitadora y reguladora del sistema de fuentes del derecho", ${ }^{62}$ y que no solo "es norma, y norma suprema, sino que, precisamente por su supremacia, se erige en fundamento y limite del resto del Ordenamiento jurídico (...)".63 De igual manera, que la regla de reconocimiento puede identificarse con (seria preferible en) la norma constitucional, tal como sostienen, en nuestro contexto, profesores como Fernández Bulté64 y Walter Mondelo. ${ }^{65}$

Por tanto, de esa multiplicidad de funciones con las que también se identifica a la Constitución (en palabras de Torres del Moral:66 Establecer un sistema de fuentes del derecho; señalar los órganos competentes y el procedimiento para la producción de dichas fuentes, entre otras), se desprende que sea esta la disposición normativa en la que deba producirse el reconocimiento positivo de las fuentes que operan en el ordenamiento jurídico cubano. Aquí enca-

62 Pérez Royo, J., Las fuentes del Derecho, Madrid, Tecnos, 2007, p. 40.

63 Torres del Moral, Antonio, Introducción al derecho constitucional, Madrid, Servicio de Publicaciones de la Facultad de Derecho de la UCM, 1996, p. 90.

64 Fernández Bulté, Julio, Teorí..., op. cit., p. 56. Afirma este autor que "todo proceso de creación del derecho (...) se inspira en la legitimidad que le confiere la constitución (...) En ese sentido esa es, sin dudas, la primera y más importante norma de reconocimiento de un ordenamiento jurídico".

65 Mondelo, Walter, Ordenamiento..., op. cit.

66 Torres del Moral, Antonio, op. cit., p. 90. 


\section{CARLOS JUSTO BRUZÓN VILTRES}

ja perfectamente entonces el reconocimiento de la jurisprudencia como fuente formal.

En el caso de Cuba, por supuesto, se requiere afianzar el principio de supremacía jurídica de la Constitución, tal como se ha insistido. Esto depende en buena medida de reconocer su directa aplicabilidad, su función jurídica más que política y el carácter ordenador que respecto al resto del ordenamiento posee, garantía además de su unidad sistémica. Junto a estas, otras cuestiones en torno a la interpretación de sus preceptos, sus mecanismos de defensa, en fin, elementos que han quedado descuidados en el plano formal y que constituyen la base para aspirar a un superior derecho.

Con este último paso se cierra el ciclo que de manera general alcanza al sistema de fuentes y que debe concretarse en un enunciado normativo, dentro de la Constitución, que contenga con precisión cuáles son las fuentes reconocidas en nuestro ordenamiento, a la par de los criterios de ordenación de las mismas, especialmente el de jerarquía y competencia. Debe contemplarse entre estas fuentes, lógicamente a la jurisprudencia, cuya definición pudiera partir de las facultades atribuidas al Consejo de Gobierno del Tribunal Supremo Popular, en el citado artículo 121 constitucional. La redacción de este enun- ciado, en sus contornos exactos, ameritaría una reflexión diferente, desde la proyección del legislador/constituyente. No obstante, esta debería considerar al menos los siguientes aspectos, que pueden resumir, en definitiva, una perspectiva particular en torno a la manifestación de esta fuente $y$, a la vez, integrar los elementos tanto doctrinales, como prácticos, que subyacen en las opiniones de teóricos, jueces y otros operadores jurídicos en Cuba:

- La jurisprudencia como fuente deriva de actos de los órganos judiciales de carácter superior, que son autoridades facultadas según disposición normativa - contempladas en la regla de adjudicación comentada-, siendo esta 
disposición la propia Constitución, sitio donde identificamos parte de la regla de reconocimiento del sistema.

- Las decisiones de estos órganos son elaboradas a partir de un modo de proceder previamente establecido en la norma, lo que garantiza su legitimidad y brinda carácter formal a esta fuente jurídica.

- La jurisprudencia - aunque puede conformarse normalmente por la reiteración de fallos de los órganos mencionados en la resolución de asuntos de similar naturaleza o la ratio decidendi de sus sentencias, que ofrecen un argumento de solución no contemplado en la ley y que se hacen valer con fuerza normativa general y obligatoria-, se expresa con mayor fuerza en nuestro contexto a través de disposiciones jurídicas propias de los órganos judiciales superiores (acuerdos, instrucciones) que imponen un modo de actuación a las jurisdicciones subordinadas o crean una regla por vía de la interpretación de la ley, que por su alcance constituye en sí misma una nueva norma jurídica.

De todos modos, el reconocimiento constitucional de la jurisprudencia como fuente - que bien pudiera aprovechar los marcos de la anunciada reforma de la norma fundamental- no es una tarea sencilla, no solo por la comentada oposición existente aún a niveles teóricos $-\mathrm{y}$ políticos-, como en los circuitos judiciales, bajo el predominio de una concepción legalista que sigue sosteniendo - quizás en términos diferentes, pero en un sentido análogo- la naturaleza contra-mayoritaria ${ }^{67}$ de la función judicial, y por extensión, de la formación jurisprudencial del derecho.

67 El término ha sido empleado por varios autores. A modo de ejemplo, y en distintos niveles de análisis, véase Ferreres Comella, Victor, "Sobre la posible fuerza vinculante de la jurisprudencia", disponible en: www. fcje.org.es/wp-content/uploads/.../2_VICTOR\%2OFERRERES.pdf (consulta de 14 de septiembre de 2013); Belloso Martín, Nuria, "Algunos dilemas sobre la jurisdicción constitucional", Revista do Direito UNISC, Santa Cruz do Sul, núm. 34, 2010, pp. 134-154. 


\section{CARLOS JUSTO BRUZÓN VILTRES}

Un enfoque con estas características trastoca lo que se ha intentado presentar aquí como una necesidad sistémica, y más aún, puede llegar a minar el argumento sostenido de que la finalidad del reconocimiento de la jurisprudencia como fuente converge con los intereses de mayor seguridad jurídica. En esta trinchera se sitúan, generalmente, quienes aprecian en las interpretaciones y decisiones judiciales -incluyendo las de nuestro supremo tribunal- discursos veleidosos, inestables, variables y circunstanciales, diametralmente opuestos a la estabilidad y generalidad que debe ofrecer la ley, como fuente predilecta de creación jurídica.

En un registro similar se ubican los que aún contemplan, con cierta esclerosis, el peligro de un "gobierno de los jueces" - abordado con anterioridad-, dada la baja factura democrática que posee tanto la elección de dichos funcionarios, como sus decisiones (en comparación con la naturaleza democrática por antonomasia conferida a los actos del legislativo). Pese a estos contra-argumentos que, por su peso en un sistema que hunde sus raíces en el legocentrismo típico de corte continental, influyen poderosamente en la determinación normativa de la jurisprudencia como fuente, la práctica va demostrando la utilidad del derecho de origen judicial que, conforme a los presupuestos expuestos, logra delinear nuevas formas en el mapa de fuentes de nuestro ordenamiento jurídico.

De paso, nada más cuestionable que la presunción anti-democrática de la función judicial, cuando el mecanismo de elección de los jueces - en el caso de Cuba- queda definido teniendo en cuenta la participación y decisión de los órganos representativos conformados a través del voto popular en los distintos procesos electorales previstos constitucional y legalmente. ${ }^{68}$ Súmese a esto la imposibilidad de

68 Así lo establece, entre otras disposiciones normativas, la Ley No. 82 de 11 de julio de 1997, de los Tribunales Populares. A este tenor, los jueces del Tribunal Supremo son electos por la Asamblea Nacional del Poder Popular —máximo órgano representativo del país-; y los del resto de los tribunales (provinciales y municipales) en las Asambleas Provinciales del 
definir a un legislador suficiente, capaz de prever y dar respuesta mediante la ley, a los supuestos que se presentan en una sociedad en constante transformación. ${ }^{69}$ Una tendencia que ha marcado el incontrovertible protagonismo judicial en la respuesta jurídica a situaciones sociales trascedentes, que escapan de la previsión y la regulación normativa desde el legislativo. ${ }^{70} \mathrm{~A}$ este dato fáctico irrebatible no ha podido sustraerse nuestra teoria y mucho menos

Poder Popular, escuchado el parecer, en el último de los casos, del Presidente de las Asamblea de la localidad donde ejercerán su función (artículo 46. 3). La representación popular en los órganos judiciales se garantiza además mediante la presencia de jueces legos (Sección Segunda, artículos 49 y siguientes).

69 Considero en este punto que la visión ofrecida por Eugenio Bulygin puede ser adaptada a la realidad jurídica cubana, cuando respecto a la creación judicial del Derecho afirma que existe una tercera posición para la cual "los jueces no crean derecho en situaciones normales, pero sí lo hacen porque crean normas generales en situaciones muy especiales" (p. 7), tesis que él defiende en el artículo "Los jueces ¿crean derecho?", Isonomía, núm. 18, 2003, pp. 7-25. El carácter especial del contexto cubano actual lo ofrece el proceso de cambios profundos en la base económica, en la sociedad y propiamente en el derecho interno, a los que se enfrenta el país, particularmente desde inicios de la presente década. El signo que lo distingue es el de una dinámica de transformación social en la que no siempre el legislador tiene un recurso inmediato para ofrecer respuestas normativas a exigencias sociales, momento en el cual ha tenido que intervenir la función judicial (como se ejemplifica a través de la instrucciones del CGTSP, que entran a regular materias específicas vinculadas a la economía, las relaciones de familia, la protección de derechos laborales, etcétera, que no siempre se encuentran debidamente tuteladas en las disposiciones jurídicas vigentes).

70 Tal protagonismo ha marcado al mismo tiempo las pautas en la evolución de la función judicial y del papel dirigente de esta en la formación jurisprudencial del derecho. Pueden servir como referencia explicativa de dicha línea evolutiva los modelos de juez expuestos por F. Ost, o el tránsito del Estado de legalidad al Estado constitucional de derechos planteado por el profesor Bhrunis Lemarie. Cfr. Ost, François, "Júpiter, Hércules, Hermes: tres modelos de juez", Doxa. Cuadernos de Filosofía del Derecho, núm. 14, 1993, pp.169-194; Bhrunis Lemarie, Roberto, "El constitucionalismo en el Ecuador", Alter Justitia, 2010, pp. 71 y 72. 


\section{CARLOS JUSTO BRUZÓN VILTRES}

nuestra práctica, especialmente aquella que se desarrolla en los tribunales.

\section{A MANERA DE CONCLUSIONES}

Existe indeterminación del sistema de fuentes del derecho en Cuba, con implicaciones en el funcionamiento del ordenamiento jurídico y particularmente en su concepción sistémica. En tal sentido puede plantearse como esquema lógico de solución a esta problemática una serie de pasos que inician con la identificación/deter- minación de los posibles modos de creación jurídica que operan en la práctica, la fijación de presupuestos y su posterior reconocimiento, preferiblemente en la norma constitucional, en la que podría expresarse parte de regla de reconocimiento de nuestro ordenamiento jurídico.

\section{Determinación Presupuestos Reconocimiento}

La jurisprudencia puede ser considerada como una de estas fuentes que efectivamente contribuyen al proceso de creación del derecho y a la integración del ordenamiento jurídico en su conjunto. En el caso de Cuba esta puede identificarse a partir de la labor del CGTSP, que supera la función interpretativa, para brindar soluciones jurídicas a situaciones no previstas por el legislador, colmando vacíos legislativos y resolviendo contradicciones normativas. Estas soluciones se desprenden de los pronunciamientos contenidos en instrucciones, acuerdos y otras disposiciones dictadas por el órgano de gobierno del Tribunal Supremo Popular, obligatorias para el resto del sistema de tribu- nales.

También este reconocimiento de la jurisprudencia como fuente debe estar sujeto a requisitos o condiciones, que se han denominado presupuestos, entre los que se encuentran el no desplazamiento del acto normativo como fuente de especial relevancia en nuestro sistema; la prohibición de acti- 
vidad legislativa paralela en sede judicial; la determi- nación de fines específicos en la formación jurisprudencial del derecho; la creación de normas jurisprudenciales a partir de disposiciones dictadas por el CGTSP y no de manera individual por parte del juez y el reconocimiento constitucional de la jurisprudencia como fuente formal.

\section{BIBLIOGRAFÍA}

Aguiló, Josep, Teoría general de las fuentes del derecho (y del orden jurídico), Barcelona, Ariel, 2000.

Álvarez Tabío, Fernando, El recurso de inconstitucionalidad, La Habana, Editorial Libreria Martí, [s/f].

Atienza, Manuel, Introducción al derecho, México, Fontamara, 1998.

Belloso Martín, Nuria, "Algunos dilemas sobre la jurisdicción constitucional”, Revista do Direito UNISC, Santa Cruz do Sul, núm. 34, 2010.

Bernal Cano, Natalia, "El poder creador del juez en la combinación o mezcla de los procedimientos constitucionales", Estudios Socio-Jurídicos Bogotá, vol. 12, núm. 1, 2010.

Bhrunis Lemarie, Roberto, "El constitucionalismo en el Ecuador”, Alter Justitia, 2010.

Bix, Brian, Filosofía del derecho: ubicación de los problemas en su contexto, trad. de Imer Flores, Rodrigo Ortiz y Juan Vega Gómez, México, UNAM, 2010.

Bobbio, Norberto, Teoria General del derecho, Bogotá, Temis, 1987.

Bruzón Viltres, Carlos Justo, "Jurisprudencia en Cuba: análisis de las consecuencias de su reconocimiento como fuente formal del ordenamiento jurídico", Opinión Jurídica, Medellín, vol. 12, núm. 23, 2013. 


\section{CARLOS JUSTO BRUZÓN VILTRES}

Bulygin, Eugenio, “Los jueces ¿crean derecho?”, Isonomia, núm. 18, 2003.

Cañizares, Fernando D., Teoría del Estado, La Habana, Pueblo y Educación, 1979.

Carbonell, Miguel, "La constitución viviente", Isonomía, núm. 35, 2011.

, "Sobre la Constitución viviente", Revista Facultad de Derecho y Ciencias Politicas, Universidad Pontificia Bolivariana de Medellín, vol. 42, núm. 117, 2012.

Carrillo, Yoel y Mondelo, Walter, "Del voluntarismo ontológico al positivismo ideológico (una lectura del pensamiento jurídico cubano)", Revista Crítica Jurídica, núm. 29, enero-junio de 2010.

Carrillo, Yoel, El proceso legislativo en Cuba. Un modelo para su análisis, tesis en opción al título de Doctor en Ciencias Jurídicas, Santiago de Cuba, 2008.

Correas, Óscar, Teoría del derecho, México, Fontamara, 2010.

Crisafulli, Vezio, "Jerarquía y competencia en el sistema constitucional de las fuentes", Revista de Derecho Constitucional Europeo, núm. 1, 2004.

David, René y Jauffret-Spinosi, Camille, Los grandes sistemas juridicos contemporáneos, trad. de Jorge Sánchez Cordero, México, UNAM, 2010.

De Lucas, Javier (ed.), Introducción a la teoría del derecho, La Habana, Ed. Félix Varela, 2006.

De Vega, Pedro, Estudios politico-constitucionales, México, UNAM-UCM, 2004.

Díez Picazo, Luis y Antonio Gullón, Sistemas de derecho civil, Madrid, Tecnos, 1994.

Domingo, Rafael, "La jurisprudencia romana. Cuna del derecho", Anales de la Real Academia de Ciencias Morales y Politicas, vol. 81, núm. 2, 2004. 
Dworkin, Ronald, Los derechos en serio, Barcelona, Ariel, 1984.

Fernández Bulté, Julio, Filosofía del derecho, La Habana, Félix Varela, 2003.

—- Teoría del Estado y del derecho, La Habana, Félix Varela, 2004, t. II.

Ferrari Yaunner, Majela, "Las lagunas jurídicas. Posiciones doctrinales y jusfilosóficas", Revista Cubana de Derecho, núm. 34, 2009.

, Los principios de legalidad y seguridad juridica como fundamentos del proceso de integración del derecho para colmar las lagunas de la ley en Cuba, tesis en opción al grado de doctor en Ciencias Jurídicas, La Habana, 2010.

Ferreres Comella, Victor, "Sobre la posible fuerza vinculante de la jurisprudencia", disponible en: www.fcje.org.es/wpcontent/uploads/.../2_VICTOR\% 2OFERRERES.pdf_[Consulta de 14 de septiembre de 2013].

Fix-Zamudio, Héctor, Veinticinco años de evolución de justicia constitucional, 1940-1965, México,[s/e], 1968.

Galiano, Grisel y González, Deyli, "La integración del derecho ante las lagunas de la ley. Necesidad ineludible en pos de lograr una adecuada aplicación del derecho", Díkaion. Revista de Fundamentación Jurídica, vol. 21, núm. 2, 2012.

García Jaramillo, Leonardo, "El "Nuevo derecho" en Colombia: ¿entelequia innecesaria o novedad pertinente", Revista de Derecho de Barranquilla, núm. 29, 2008.

Garcini, Héctor, Derecho Administrativo, La Habana, Pueblo y Educación, 1986.

González Jácome, Jorge, "El problema de las fuentes del derecho: una perspectiva desde la argumentación jurídica", Vniversitas, núm. 112, 2006. 


\section{CARLOS JUSTO BRUZÓN VILTRES}

Grillo Longoria, Rafael, Derecho Procesal Civil. Teoría general del proceso, La Habana, Pueblo y Educación, 1993, t. I.

Häberle, Peter, El Estado constitucional, México, UNAM, 2001.

Hart, H. L. A., El concepto de derecho (trad. de G. Carrió), Buenos Aires, Abeledo Perrot, 1963.

- $\longrightarrow$ Post scriptum al concepto del derecho (ed. por P. Bulloch y J. Raz), México, UNAM, 2000.

Hennig Leal, Mônia Clarissa, "La jurisdicción constitucional entre judicialización y activismo judicial: ¿existe realmente "un activismo" o "el activismo"?, Estudios Constitucionales. Santiago de Chile, vol. 10, núm. 2, 2012, disponible en: http://dx.doi.org/ 10.4067/S0718-52002012000200 011 [consulta de 12 de agosto de 2013].

Hierro, Liborio L., "El imperio de la ley y la crisis de la ley", Doxa. Cuadernos de Filosofía del Derecho, núm. 19, 1996.

Lafuente Balle, José Ma., La judicialización de la interpretación constitucional, Madrid, Colex, 2000.

Laporta, Francisco J., "Imperio de la ley. Reflexiones sobre un punto de partida de Elias Diaz", Doxa. Cuadernos de Filosofía del Derecho, núms.15-16, 1994.

Legaz, Luis, Filosofía del derecho, Barcelona, Bosch, 1961.

López Medina, Diego E., "Tres caminos históricos en la formación de la jurisprudencia en América Latina: Recepción y vicisitudes del concepto de "doctrina legal" en la región”, en GONZÁlEZ, A. y DEL Río, J. (comps.), Discusión jurídica contemporánea desde Michoacán, México, Tribunal Electoral del Estado de Michoacán, 2011.

, El derecho de los jueces (10 ma. reimpr.), Bogotá, Legis, 2011. 
- Teoría impura del derecho. La transformación de la cultura jurídica latinoamericana, Bogotá, Legis, 2013.

MacCormick, Neil., "Orden espontáneo e imperio de la ley: algunos problemas", Doxa. Cuadernos de Filosofía del Derecho, núm. 6, 1989.

Magallón Ibarra, Jorge M., El renacimiento medieval de la jurisprudencia romana, México, UNAM, 2002.

Magallón Ibarra, Jorge M., La senda de la jurisprudencia romana, México, UNAM, 2000.

_- Los sonidos y el silencio de la jurisprudencia mexicana, México, UNAM, 2004.

Maraniello, Patricio, "El activismo judicial, una herramienta de protección constitucional", Pensar en Derecho, núm. 1, 2012.

Matilla Correa, Andry, "Comentarios sobre las fuentes del derecho administrativo cubano (excepto el reglamento)", en Castanedo, A. et al., Temas de derecho administrativo cubano, La Habana, Félix Varela, 2006.

Méndez López, Josefina, El modelo de creación de leyes en Cuba, tesis en opción al título de doctor en Ciencias Jurídicas, Santiago de Cuba, 1999.

Mendoza Díaz, Juan, et al., Lecciones de derecho Procesal Civil, La Habana, Félix Varela, 2001.

Mondelo, Walter, "Partir del pasado para explorar el futuro", Revista Temas, núm. 64, julio-diciembre de 2010.

, Ordenamiento jurídico, Constitución y regla de reconocimiento, tesis en opción al grado de doctor en Ciencias Juridicas, Santiago de Cuba, 2003.

Moreso, José J. y Vilajosana, Josep M., Introducción a la teoría del derecho, Madrid-Barcelona, Marcial Pons, 2004. 


\section{CARLOS JUSTO BRUZÓN VILTRES}

Ost, François, “Júpiter, Hércules, Hermes: tres modelos de juez", Doxa. Cuadernos de Filosofía del Derecho, núm. 14, 1993.

Pérez Carrillo, Juan R., "Causas de indeterminación en el sistema de fuentes del derecho", Problema. Anuario de Filosofía y Teoría del Derecho, México, núm. 4, 2004.

Pérez Gallardo, Leonardo et al., Estudios de derecho civil cubano, Madrid, Consejo General del Notariado, 2002.

Pérez Gallardo, Leonardo, "Introducción al derecho civil”, en Valdés, Caridad et al., Compendio de derecho civil, La Habana, Félix Varela, 2007.

Pérez Royo, Javier, Las fuentes del derecho, Madrid, Tecnos, 2007.

Prieto Valdés, Martha, "En pos de la aplicabilidad directa de la Constitución cubana de 1976 (un breve comentario)", Ius. Revista del Instituto Jurídico de Puebla, núm. 21, 2008.

, El derecho, la Constitución y su interpretación, tesis en opción al grado de doctor en Ciencias Jurídicas, La Habana, 2002.

Raz, Joseph, The Authority of Law, Oxford, Oxford University Press, 1979.

Rodríguez Sánchez, Ciro F. y R. Hernández, "La jurisprudencia como fuente complementaria del derecho", Memorias de la IV Conferencia Científica sobre el derecho, Santiago de Cuba, Universidad de Oriente, 1997.

Tamayo y Salmorán, Rolando, "Jurisprudencia y formulación judicial del derecho (Principium)", Isonomía, núm. 21, 2004.

Tamayo y Salmorán, Rolando, Razonamiento y argumentación jurídica. El paradigma de la racionalidad y la ciencia del derecho, México, UNAM, 2003.

Teixeira, Anderson, "Ativismo judicial: nos limites entre racionali- 
da de jurídica e decisão política", Revista Direito GV, vol. 8, núm. 1, 2012.

Torres del Moral, Antonio, Introducción al derecho Constitucional, Madrid, Servicio de Publicaciones de la Facultad de Derecho de la UCM, 1996.

Torres Zárate, Fermin, "La jurisprudencia (su evolución)", Alegatos, núm. 72, 2009.

Vallet de Goytisolo, Juan, "El razonamiento judicial", Anales. Real Academia de Jurisprudencia y Legislación, 39, Madrid, Dykinson S.L., 2009.

Vega Gómez, Juan, “El positivismo excluyente de Raz”, Boletín Mexicano de Derecho Comparado, vol. 37, núm. $110,2004$.

Vilajosana, Josep, El significado politico del derecho, México, Fontamara, 2005.

Villabella, Carlos, Historia constitucional y poder politico en Cuba, Camagüey, Ácana, 2009.

Yowell, Paul, "Legislación, Common Law y la virtud de la claridad", Revista Chilena de Derecho, vol. 39, núm. 2, 2012. 